\title{
Psicanálise e UNIVERSIDAde: \\ REFLEXÕES SOBRE UMA CONJUNÇÃO AINDA POSSÍVEL
}

Ana Cristina Figueiredo ${ }^{\star}$

\begin{abstract}
Resumo
O texto aborda a relação entre psicanálise e universidade. Inicia com breve histórico no Rio de Janeiro nos anos 1960 e examina diferentes possibilidades da psicanálise no ensino de graduação e pós-graduação. Na graduação temos um saber "sobre" a psicanálise. É diferente quando envolve um trabalho clínico ou uma elaboração feita por psicanalista nos cursos de mestrado ou doutorado. O argumento é construido a partir dos "quatro discursos" formulados por Lacan e discute a transmissão da psicanálise por meio do ensino. Essa transmissão é de um desejo de saber marcado pela falta, que é o modo de saber que concerne à psicanálise.
\end{abstract}

Palavras-chave: Psicanálise. Universidade. Transmissão. Desejo de saber.

\section{Psychoanalysis AND UNIVERSITY: \\ REFLECTIONS ON A STILL POSSIBLE CONJUNCTION}

\begin{abstract}
This paper approaches the relation between psychoanalysis and university. It begins with a historical approach in Rio de Janeiro since the 60's and examines the possibilities of psychoanalysis in undergraduate and postgraduate levels. The former only presents knowledge 'about' psychoanalysis. The latter may involve clinical work or a psychoanalyst's working through a master or doctoral thesis. The text presents the 'four discourse' theory formulated by Lacan and discusses the transmission of psychoanalysis through teaching. It puts forward that this transmission is of a 'wish for knowledge' based on its lack which is the core of psychoanalytical approach to knowledge.
\end{abstract}

Keywords: Psychoanalysis. University. Transmission. Wish for knowledge.

\footnotetext{
* Psicanalista; Professora do Programa de Pós-graduação em Teoria Psicanalítica e do Instituto de Psiquiatria IPUB, UFRJ; Doutora em Saúde Coletiva pelo IMS/UERJ. Endereço: Universidade Federal do Rio de Janeiro, Instituto de Psiquiatria, Programa de Psiquiatria. Av. Venceslau Brás, 71 - fundos - Botafogo. CEP: 22290-140 - Rio de Janeiro, RJ - Brasil.

E-mail: ana.cfigueiredo@terra.com.br
} 
Desde Freud pedindo reconhecimento através de suas incursões à América na Clark University, onde percebeu a distância entre pedagogia e psicanálise e o equívoco americano, e também como docente convidado em Viena sem garantias universitárias para levar adiante seu projeto, até Lacan com seu polêmico Departamento de Psicanálise em Paris VIII as relações entre psicanálise e universidade sempre foram bastante controversas, mas nem por isso menos significativas. Se, para Freud, resta à Universidade apenas um saber sobre a psicanálise, e para Lacan, fica a burocracia do Discurso Universitário como seu paradigma, não temos mais o que dizer a respeito disso. Entretanto, a história nos mostra algo mais complexo, que exige um exame mais cuidadoso e menos apressado, já que não podemos nos render aos preceitos e preconceitos, o que seria uma direção realmente anti-psicanalítica. Penso que essa discussão não deve simplesmente ser abandonada em nome da pureza da psicanálise ou de proteções contra sua conspurcação pelo meio universitário.

Inicio trazendo o problema para nosso contexto, tratando um pouco do caso brasileiro, mais especificamente de como se deu a difusão da psicanálise na universidade no Rio de Janeiro. Porém, não acredito que este seja um caso isolado ou uma exceção. Antes, temos uma história a contar que nos aponta o enodamento de ambas e seus efeitos na formação analítica. Em seguida, avanço a discussão à luz dos quatro discursos propostos por Lacan para dimensionar o que está em jogo no binômio psicanálise-universidade, tendo como questão central o que se pode transmitir desse ensino. Tomo a via da psicanálise em extensão sabendo que esta se articula topologicamente à psicanálise em intensão.

\section{UM POUCO DE HISTÓRIA: O CASO BRASILEIRO EM SEUS PRIMÓRDIOS ${ }^{1}$}

As primeiras incursões da psicanálise na universidade no Rio de Janeiro ocorreram por volta do ano 1956, quando Padre Benko fundou o primeiro curso de Psicologia na PUC/RJ. Entusiasta da psicanálise, convida como docentes do curso dois importantes personagens da história da psicanálise e da psicologia no Brasil respectivamente: Roberto Azevedo, psicanalista da Sociedade Brasileira de Psicanálise de São Paulo (SBPSP), professor da disciplina "técnica psicanalítica", e Elisa Veloso, psicóloga fundadora da profissão no Rio de Janeiro, que trabalhava no atendimento a crianças com orientação psicanalítica e com supervisão de psicanalistas da Sociedade Brasileira de Psicanálise do Rio de Janeiro (SBPRJ).

Em março de 1960, foi criado também na PUC/RJ o Centro de Orientação Psicopedagógica (COPP) cujo objetivo era fornecer "orientação a crianças, adolescentes e familiares com problemas". Este é o primeiro serviço de atendimento clínico (diagnóstico e terapia) à população carioca criado numa universidade utilizando estagiários de psicologia. Os psicanalistas eram ligados à SBPRJ e compunham o grupo de professores/supervisores selecionando os estagiários mais aptos. O vínculo desses psicanalistas com a universidade não era muito claro. Às vezes eram apenas convidados para trabalhar remunerados como prestadores de serviços. 
Curioso observar que a seleção dos estagiários tinha como requisito obrigatório estar em análise, e constava de três entrevistas com os psicanalistas. Este era o único critério de avaliação.

O modelo dominante na época era o da escola inglesa a partir das teorias de Melanie Klein, com atendimento de três a quatro vezes por semana; análise das relações de objeto, dos processos de identificação e a ênfase na interpretação da transferência.

Na primeira metade dos anos 1960 a PUC foi pioneira na formação de psicólogos cujo suporte teórico foi dado basicamente pela psicanálise da época. Além disso, havia serviços de atendimento infanto-juvenil ligados à Secretaria de Educação, um deles (COI) funcionando no IPUB/UFRJ sob a supervisão de duas psicanalistas da SBPRJ: Mara Salvini e Ana Elisa Mercadante.

Nesse período, psicanalistas e psicólogos estão envolvidos no ensino e na supervisão dos alunos. Os próprios psicólogos já haviam feito seu percurso como analisandos e alunos dos psicanalistas médicos. As Sociedades da IPA não aceitavam psicólogos para formação até 1980, com algumas exceções. Paralelamente, houve a regulamentação da profissão de psicólogo com a criação do CFP em 1971.

Psicanálise, psicologia e pedagogia se misturam, se confundem, mas a hegemonia tanto política quanto teórica é da psicanálise produzida nos moldes da IPA, o que nos leva a crer que impera aí o discurso universitário presente em toda a formação dos psicanalistas da época. Mas não podemos nos esquecer que também aí havia uma estreita relação entre analistas e analisandos que trabalhavam na universidade e ainda dos serviços de atendimento que sustentavam uma clínica com os instrumentos disponíveis na época. Não podemos dizer que não havia qualquer resquício de psicanálise, mas podemos afirmar que havia um trabalho em direção à "psicanálise possível” dada pelo paradigma kleiniano.

\section{A PSicologia PSICANAlítica dos PSICÓlogos E A UNIVERSIDAde}

Nos decorrer dos anos 1970 consolida-se a hegemonia da psicanálise da escola inglesa aliada à leva argentina de psicanalistas que migraram para o Brasil ainda na tradição da escola inglesa. Houve dois períodos dessa migração: entre 1970/1972, os kleinianos, discípulos de Pichon-Rivière; entre 1975/1978, os marxistas, perseguidos em seu país e que romperam com a IPA questionando sua hegemonia. A história se desdobra nos anos 1980 numa dupla virada: do kleinismo para uma abertura ao movimento lacaniano, e do elitismo social para a "abertura" dos consultórios de psicanálise e da formação de psicanalistas.

Ainda em 1971, um grupo de psicólogos que se analisavam com psicanalistas e já tinham uma prática clínica constituída estabelecem uma parceria com a PUC/RJ por intermédio do Dr. Carlos Paes e Barros, na época diretor do departamento de psicologia e psicanalista do Instituto de Medicina Psicológica 
(IMP), para a criação de um Curso de Especialização em Psicologia Clínica. Esse curso permaneceu na década de 1970 com a função de "formar" "psicólogos clínicos psicanalíticos".

A formação analítica nas Sociedades da IPA era vetada aos psicólogos. A universidade então vem cumprir essa função ambígua com o apoio de alguns psicanalistas da SPRJ, qual seja: formar profissionais "psicanalíticos", mas não reconhecidos como psicanalistas. Uma questão de política corporativista, que se revestia de diferenças teórico-técnicas artificiosas e infundadas para caracterizar o que seria permitido aos psicólogos como: menor freqüência e duração do tratamento, restrições ao uso do divã, ênfase em interpretações ditas "menos profundas"(?), técnicas “pré-verbais" (?), não trabalhar a "regressão" e avaliar os limites de tolerância da angústia (?) etc. Enfim, nada disso era uma diferença positivada. A psicanálise ia-se tornando mais idealizada e mais cobiçada como o melhor método para a chamada "psicologia clínica", porém, sem a legitimação dos grupos e associações formadoras de psicanalistas. Convém observar que outros cursos de especialização surgiram nos anos 1980/1990, já com outra perspectiva.

Dois aspectos caracterizam a "psicologia psicanalítica": 1) os psicólogos clínicos passam de consumidores a produtores, ou re-produtores, da psicanálise, reivindicando o status de psicanalista; 2) o próprio campo psicanalítico se amplia atingindo um certo ecletismo de teorias e práticas para além de seus próprios limites.

A partir de 1980, a formação em psicanálise estende-se aos psicólogos e o critério de ortodoxia não mais se sustenta no eixo político-profissional, mas se desloca para o eixo teórico-clínico. É preciso redefinir a psicanálise, reencontrála para praticá-la e a universidade não é considerada um bom lugar para isso. As associações de formação psicanalítica proliferam e disputam a hegemonia da psicanálise, oscilando entre o discurso universitário e o discurso histérico.

Nos anos 1990 intensifica-se uma outra política que afirma que a formação deve ser voltada para o atendimento em instituição. Dessa vez a psicanálise corre o risco de perder sua especificidade, não mais para justificar a profissionalização dos psicólogos, mas para o atendimento à população de baixa renda que chega aos ambulatórios e aos serviços de saúde mental.

Nesse mesmo período, o movimento lacaniano se consolida, por meio da disseminação do ensino de Lacan, para recolocar a questão de ser ou não psicanalista em outro patamar e retomar a ortodoxia da psicanálise na direção de seus conceitos fundamentais e de sua clínica. Essa diferença é vital para repensarmos a psicanálise na universidade. Lacan soube tirar partido dela apesar de sua posição não muito favorável. 


\section{A psicanálise na Universidade: entre o ensino e a}

\section{TRANSMISSÃO}

Antes de tratarmos do ensino da psicanálise na universidade, formulemos a pergunta que antecede essa questão e situa o verdadeiro problema a ser enfrentado: o que se transmite do que se ensina da psicanálise?

Sabemos que a transmissão ultrapassa o ensino na medida em que se dá para além dele, na análise de cada um, na supervisão em que o analista dá provas de sua clínica, enfim, "psicanálise não se aprende só na escola", mas também nela. E foi aí que Lacan fundou sua escola, uma década depois de iniciar seu ensino.

Em 1957, quando Lacan escreve "A Psicanálise e seu Ensino", 2 fala a um público de filósofos interessados em psicanálise, mas nem por isso mais tocados pelos efeitos da descoberta do inconsciente na cultura, e dirige sua crítica ácida aos psicanalistas pós-freudianos dominantes nos anos 1950. Se era sabido que a psicanálise trata da sexualidade, os psicanalistas da IPA teriam se encarregado de promover uma "domesticação do sexual", reduzindo-o a uma dinâmica psicossociológica, e fomentar antigos e novos dualismos (muito caros a alguns filósofos) insustentáveis na psicanálise, tais como: instintivo $\mathrm{x}$ intelectual; automático $\mathrm{x}$ controlado; intuitivo x discursivo; passional x racional; elementar x integrado. A partir desses dualismos, se fazia uma clínica ortopédica que visaria a um ensino controlado de "como fazer" a passagem de um estado a outro.

Lacan (1957/1998, p. 438) abre seu texto com o item: “A Psicanálise, o que ela nos ensina...", já numa inversão da proposta anterior. E destaca primeiramente que no inconsciente, que nada tem de profundo e nem por isso menos acessível ao aprofundamento consciente, isso fala. E ainda, que a verdade do inconsciente está nas entrelinhas, que sintoma não é simbolismo, e que não se deve confundir a contingência do objeto, indicada por Freud, com o "ambientalismo". Dito isto, ele provoca: como ensinar o que a psicanálise nos ensina? É preciso partir de alguns pontos irredutíveis.

O primeiro deles é que o inconsciente é sobredeterminado apenas porque está na ordem da linguagem, e a linguagem advém não como instrumento para a fala, mas como algo que pertence ao campo do Outro. Sendo assim, é preciso invocar o Outro, como terceiro, de quem o sujeito recebe sua mensagem invertida, e esquecida. O inconsciente é esse discurso do Outro, e é a ele que se dá a palavra, no limite, a verdade do sujeito. Fazer falar o Outro no sujeito é a abertura ao inconsciente. Esse Outro "é exigido para situar no verdadeiro a questão do inconsciente" (LACAN, 1957/1998, p. 455).

Para situar o inconsciente e suas formações, Lacan parte do simbólico para destacar o sintoma com sua função significante, bem diferente do simbolismo praticado na época. Se o sintoma pode ser lido, é porque já está inscrito num processo de escrita, de uma sintaxe, de uma química silábica, como dizia Freud. 
Um outro ponto irredutível é a função do real. O real se introduz aí como falta ao simbólico, seu próprio limite, por onde ganha existência. Lacan (1957/1998, p. 440) adverte:

Esse Outro, contudo, fica apenas a meio caminho de uma busca que o inconsciente deixa transparecer por sua arte difícil, e da qual os paradoxos do objeto em Freud revelam a ignorância sumamente advertida; pois a entendê-lo, é por uma recusa que o real ganha existência; aquilo de que o amor faz seu objeto é o que falta no real; aquilo em que o desejo se detém é a cortina por trás da qual essa falta é figurada pelo real.

Voltando à questão do ensino, no retorno a Freud, Lacan não perdoa os que vieram depois dele e fizeram do ensino da psicanálise um mero ensino profissional, como numa "escola de dentistas" (LACAN, 1957/1998, p. 459), expressão que teria sido usada para justificar esse ensino. E constata:

Freud conseguiu o que queria: uma conservação puramente formal de sua mensagem manifesta no espírito de autoridade reverente com que se efetuam suas mais evidentes alterações. Não há, com efeito, uma só balela proferida na mixórdia insípida que é a literatura analítica que não tome o cuidado de se apoiar numa referência ao texto de Freud, de tal sorte que, em muitos casos, se o autor não fosse também um afiliado da instituição, não se encontraria outra marca de qualidade analítica de seu trabalho.

Foi graças a isso [...] que os conceitos fundamentais de Freud permaneceram inabaláveis. Eles devem seu valor de significantes não presentes ao fato de, em grande parte, haverem continuado incompreendidos (LACAN, 1957/1998, p. 459-460).

Seu apelo pretende retomar a verdade freudiana de modo radical. Não basta citá-lo, reproduzi-lo, como "referência", pois isso não garante que seu texto seja compreendido e que sua verdade seja realmente atingida. Assim, Lacan (1957/1998, p. 460) termina seu discurso com uma indicação contundente:

Qualquer retorno a Freud que dê ensejo a um ensino digno desse nome só se produzirá pela via mediante a qual a verdade mais oculta manifesta-se nas revoluções da cultura. Essa via é a única formação que podemos pretender transmitir àqueles que nos seguem. Ela se chama: um estilo.

Lacan aponta o estilo como o caminho para retomar os significantes freudianos e deles fazer um ensino; logo, o que se transmite é um estilo. Assim, avançamos nossa questão para esse ponto: fazer do sintoma um estilo é o objetivo final de uma análise. Mas é preciso manter o ensino mesmo assim, antes 
de um fim, tendo como fim uma transmissão possível que nos lance para além da "escola de dentistas". O estilo não é um ethos. O ethos é geral, normativo, evoca princípios para uma ação, como um estilo de vida, por exemplo. O que se transmite em psicanálise não é um estilo de vida, mas antes o que do sintoma se torna estilo como irredutível para cada um. Esta é mais uma questão para a transmissão em uma análise.

Voltemos ao ensino, e o que se pode transmitir aí onde o estilo comparece incluindo o sintoma do professor: ensinar. Como nos deixarmos ensinar pela psicanálise, já que ela nos ensina, é o que nos provoca agora.

\section{ENSINO E ESCOLA}

Em 1967, após Lacan ter fundado sua própria escola, ${ }^{3}$ era preciso avançar no ensino da psicanálise para a formação do psicanalista. Em seu famoso texto "Proposição de 9 de outubro de 1967 - sobre o psicanalista da escola", Lacan (1967/1981) insiste em afirmar que se a Escola é uma garantia para a formação do psicanalista, entretanto, existe "um real em jogo" na própria formação sobre o qual se funda qualquer escola ou associação, que provoca o mal-estar. Freud já havia apontado esse mal-estar justamente ao falar da cultura humana em suas diferentes manifestações. É concebível, então, que esse real provoque seu próprio desconhecimento, sua negação sistemática (LACAN 1967/1981, p. 30).

O que nos interessa disto é que para todo e qualquer ensino esse real está lá, no equívoco do que se pode apreender, mas também no cerne da letra, como o que resta a transmitir. Ainda na "Proposição..." Lacan (1967/1981) vai indicar a política da segregação do lado do real (a figura usada é a do campo de concentração) alimentada pelo imaginário da formação de grupos. Curiosa formulação que nos põe a pensar o que pode advir de um ensino levado a cabo no dogmatismo sustentado pela transferência em sua dimensão imaginária, na haînamoration inevitável levada às últimas conseqüências. $\mathrm{Na}$ universidade estaríamos mais protegidos disso? É uma questão importante que retomaremos mais à frente. É nesse ponto que a transferência como suposição de saber interessa não apenas ao dispositivo analítico, mas a qualquer forma de ensino, afinal de contas, Lacan é explícito em situar o primeiro como a psicanálise em intensão (a clínica "estrito senso"), e o segundo como a psicanálise em extensão (a psicanálise no mundo) na topologia moebiana do oito interior. Isto é, numa seqüência em que não há dentro e fora, nem descontinuidade: um laço envolve o outro num movimento contínuo.

Se a psicanálise em intensão opera com as identificações imaginárias (os pós-freudianos são um bom exemplo), conseqüentemente a psicanálise em extensão ocorre nos efeitos de grupo. Sabemos que esse não é um bom caminho para a psicanálise. A propósito disso, Lacan chega a sugerir que se estude, por exemplo, a função do sujeito suposto ao saber na Igreja ou no Exército, apontados por Freud como instituições que sustentam a psicologia de grupos (Massenpsychologie) centrada na figura do líder (LACAN, 1967/1981, p. 41). 
A continuidade entre intensão e extensão remete-nos a um problema: o que teríamos da psicanálise em intensão na universidade que permitiria essa continuidade topológica sem a qual estamos fora do campo psicanalítico?

Freud foi claro ao afirmar que na universidade só é possível um ensino "dogmático crítico" a respeito da psicanálise. Mas também alertou para a possibilidade de haver um ambulatório ou enfermaria que pudesse oferecer um campo de intervenção propício ao exercício da psicanálise. Aí se poderia pensar num saber "a partir" e não apenas "sobre". 4

Lacan complexifica a relação entre saber e psicanálise. Inicialmente, formula o cerne da transferência não mais em seus efeitos imaginários como o "amoródio" ou seu correlato, a "corrente terna", como Freud indicava. A formulação do sujeito suposto ao saber para definir a transferência põe em jogo a dimensão do saber na estrutura, abrindo uma nova possibilidade de situá-lo em relação ao sujeito como saber inconsciente, em seu paradoxo de saber não sabido, saber do Outro. E também como saber suposto ao texto. Assim, não é o saber do analista (ou do professor) que interessa, como era preconizado entre os pós-freudianos. Antes, o que interessava era a relação dual com seu substrato ideal, que era a identificação com o analista (ou com o didata que ensina). Esse modelo persiste ainda hoje, mas não é predominante no campo psicanalítico.

Dois anos depois, Lacan postula o seu "quadrípode"5 seu esquema de "quatro patas", seus "quatro improvisos" que são os quatro discursos, com quatro elementos dispostos em quatro lugares estruturais, que fazem uma rotação de quatro movimentos a partir dos quais se articulam. Os discursos dominam e governam tudo o que pode surgir das falas e são eles mesmos estruturas sem palavras para além da enunciação. O que nos interessa nessa montagem não é tanto subsumir as relações humanas a um determinado esquema, mas sim que relação ao saber pode se estabelecer em suas mutações nos diferentes discursos, já que o saber é um dos quatro elementos que se articula aos demais. São eles: o discurso do mestre ou amo, que convoca o saber no lugar do Outro, do trabalho, para nele intervir por intermédio de $\checkmark$ que tem por efeito $\exists$ no lugar da verdade, é o discurso da própria constituição do sujeito; o discurso universitário que tem o saber no lugar do agente ou semblante, de onde em geral é ensinado, no movimento de tout savoir, que tem o duplo sentido de um saber todo, completo, e de tudo saber, saber sobre tudo, universitas literarum; o discurso histérico que interroga o Outro como o mestre para produzir o saber seja como resto ou perda, seja como produto, no sentido de uma elaboração; e o discurso analítico, que Lacan diz ser o último, o novo, que se distingue por formular a pergunta: para que serve essa forma de saber que rejeita e exclui a dinâmica da verdade? (LACAN, 1969-70/1992, p. 85). Aí está o - no lugar da verdade, movendo uma análise.

Na intensão, trata-se do saber que se tece na cadeia significante $\leftrightarrow$ provocado por $\Sigma \mathrm{q}$, um significante qualquer do analista que deve remeter à verdade do sujeito por meio da cadeia associativa ("associação livre") que, por ser menos livre, é marcada pelas trilhagens (Bahnungen) do inconsciente. 
Na extensão, a suposição de saber está presente no ensino da psicanálise. Na escola, essa suposição é ao ensino de Lacan, ao texto de Freud. Na universidade, essa suposição também pode se dar na mesma direção, mas há um dado novo que remete a questão do saber a uma produção provocando o Outro. Aqui situamos o discurso histérico como balizador da experiência de produção de saber a partir da interrogação do que está estabelecido, dos significantes mestres que se apresentam. Este é o espírito do pesquisador: interrogar o significante mestre, ousar desafiá-lo com seu olhar inquieto e inquiridor, para produzir saber. O discurso histérico que aí comparece, remete o sujeito à sua verdade. Está em jogo para o sujeito formular uma questão à psicanálise para buscar uma resposta ao que foi formulado como "problema de pesquisa" que revela algo de seu sintoma.

\section{A PSICANÁLISE NA EXPERIÊNCIA UNIVERSITÁRIA:}

\section{UMA CONJUNÇÃO POSSÍVEL}

$\mathrm{Na}$ experiência universitária com a psicanálise, temos diferentes inserções no ensino. Nos cursos de graduação, só é possível um saber sobre a psicanálise, não há como alterar isso. O que se pode fazer é recolher os efeitos de um primeiro contato com a psicanálise para cada um. Um psicanalista que se encontra na função de ensinar estará marcado pelo que a psicanálise nos ensina e, portanto, pode recolher os efeitos desse ensino em vez de reduzir os alunos a unidades de valor com suas notas e seus deveres de casa.

Na pós-graduação temos uma situação bem mais complexa. O psicanalista que procura um curso de mestrado ou doutorado pode querer apenas tornar-se professor, seguir a "carreira" universitária, ou seja, ser tomado pelo semblante de saber. Mas pode também, e isso acontece com mais freqüência hoje, querer elaborar algo de seu percurso na psicanálise, que não é da ordem nem de uma análise pessoal (certamente contém seus efeitos) nem de uma demanda à instituição em que fez sua formação. Sua demanda ao saber universitário o remete ao desafio de ele próprio ter de dar uma resposta.

A psicanálise se difunde por meio do ensino universitário nesses diferentes níveis de atuação. Desde os cursos de graduação que mantêm em seu currículo várias disciplinas com o tema da psicanálise, até cursos de pós-graduação tanto em nível profissionalizante, tais como as especializações, que proliferaram na última década, quanto em nível de mestrado e doutorado, incluindo aí um dado novo: a pesquisa, que é o cerne do trabalho universitário com suas regras, seus métodos estritos, mas é preciso pensar seu lugar e função para a psicanálise. É paradoxalmente aí que se pode inscrever uma outra relação com o saber que não se restringe ao discurso universitário. Como situar a psicanálise nesse quadro? Tomemos esses diferentes níveis de ensino com suas peculiaridades para situar a psicanálise em cada um e em relação aos quatro discursos propostos por Lacan. 


\section{GraduAÇão: UM SABER SOBRE A PSICANÁliSe}

Nos cursos de graduação, a maioria das disciplinas ainda mantém nomes da psicologia clínica, mas o conteúdo programático é eminentemente da teoria psicanalítica. Já existem disciplinas explicitamente referidas à psicanálise pela reforma curricular de vários cursos, mas isso não altera a relação com o saber.

Os psicanalistas, por sua vez, estão mais interessados em participar do ensino de graduação, mas muitos mantêm uma atitude de "dar aulas de psicanálise" sem qualquer preocupação em relação aos efeitos desse ensino sobre o aluno. Sem dúvida só podem mesmo oferecer um saber sobre a psicanálise. Imerso no discurso universitário, o professor é o agente que faz semblante de saber ( $)$ que se dirige ao aluno que trabalha e conta como "unidade de valor"; o saber é avaliado e tem como produção e produto o sujeito dividido $(\exists)$. Podemos dizer que está dividido em relação ao saber que busca obter com a prometida titulação.

Quanto à psicanálise, é freqüente a observação de que os alunos desenvolvem resistências análogas às que Freud mencionou como sendo as de seus pacientes em análise. E esse primeiro contato com os conceitos psicanalíticos, seu uso e finalidade, é determinante para novas resistências ou para uma possível abertura ao saber do inconsciente.

As atividades de estágio na clínica podem oferecer uma primeira chance para uma relação diferente com a psicanálise, algo a partir de um real que se apresenta na demanda feita ao aluno pelo paciente que busca atendimento, e o coloca pela primeira vez em posição de dar algum destino a essa demanda que lhe é dirigida. A questão que permanece é como colher esses efeitos entre os alunos e fazê-los saber disso na verdade de cada um, sem cair na armadilha de uma "análise selvagem" no espaço de ensino, mas para localizar o que foi possível de uma transmissão nesse primeiro momento.

\section{ESPECIALIZAÇÃO: UM SABER A PARTIR DA PSICANÁLISE?}

Nos cursos de especialização, que são cursos de pós-graduação lato sensu, a situação dos alunos é diferente do que ocorre na graduação, pois aí se encontram profissionais autorizados pela própria universidade como psicólogos, médicos, assistentes sociais etc. que escolhem determinado curso para avançar em sua formação e definir melhor seu campo de trabalho. A escolha pressupõe um novo momento para a suposição de saber dirigida a determinada universidade, ou curso, ou grupo de professores em relação à psicanálise. Nesse ponto, podemos estar novamente diante de um querer saber mais sobre a psicanálise mantendo o imperativo do discurso universitário. Mas podemos, por outro lado, trabalhar com a escolha de cada sujeito em direção à psicanálise. Muitas vezes, a demanda ao curso se faz a partir de efeitos da análise pessoal do aluno, ou do encontro com a clínica, seja através de um fracasso ou de um novo desafio como, por exemplo, o encontro com a psicose. 
Na direção à psicanálise, o caminho de uma formação em alguma instituição psicanalítica é o mais direto e o mais plausível, mas muitas vezes encontramos nesses cursos pessoas que fazem sua formação e ainda assim buscam a universidade. Podemos atribuir isso exclusivamente aos efeitos do discurso universitário? Creio que não, até porque esse discurso também se apresenta em maior ou menor grau nas instituições de formação de analistas, e ainda, de acordo com o depoimento de vários alunos também em formação, a universidade permite um "livre pensar", que pode ser entendido como uma tomada de posição crítica em relação aos efeitos nefastos da transferência imaginária, muito intensa nessas instituições, que impede a circulação de saber. Em outras palavras, podemos dizer que a cristalização da transferência impede o giro dos discursos, no processo de transmissão da psicanálise e, conseqüentemente, mudança de posições subjetivas.

O encontro com a clínica, que ocorre de modo singular para cada um, possibilita o giro do discurso universitário para o discurso analítico. Se há um ambulatório ou enfermaria como parte da oferta da universidade ao aluno, há uma clínica em jogo, um risco e, portanto, uma aposta. Aí está o que Freud se refere como o "a partir" da psicanálise. ${ }^{6}$

Quanto à supervisão, temos aqui uma dimensão fundamental do ensino na direção de uma transmissão. É apenas por meio desse trabalho que se pode fazer furo no saber como semblante que marca o discurso universitário. Ao mesmo tempo esse é o maior desafio do ensino: transformar um saber sobre a psicanálise em saber psicanalítico a partir do que é endereçado ao supervisor pelo aluno que, nesse momento, se encontra em posição de sujeito dividido. ${ }^{7}$

Em ambos os casos, tanto na graduação quanto na pós, principalmente nesse último caso, em que a escolha do aluno se dá num outro momento de seu encontro com a clínica, a supervisão é fundamental para fazer operar o giro nos discursos. Do discurso universitário, que sustenta o semblante de $\boldsymbol{V}$, ao discurso analítico, que recoloca o saber no lugar da verdade, num quarto de giro regressivo na operação dos discursos, o que temos é o deslocamento da função e uso do saber fazendo aparecer o sujeito dividido $(\exists)$, não como produto da intervenção do saber, mas sim do lado do outro, do trabalho, de onde pode ser interrogado para prestar contas de sua clínica.

Se a proposta do curso for somente de fundamentação teórica, podemos encontrar alunos com diferentes níveis de conhecimento, mas também de transferência com a psicanálise, e aí temos a possibilidade de um estudo crítico mais do que dogmático. Não no sentido de um criticismo estéril que visaria destituir a psicanálise de seu lugar específico na cultura, mas no sentido de uma elaboração, de retomada de um saber referencial para produzir um saber textual: um certo Durcharbeitung como trabalho através dos conceitos, retomando a psicanálise como para produzir $\downarrow$ e remeter esse saber à sua verdade. Isso seria como operar um giro do discurso histérico para o discurso analítico com relação ao saber. 
O problema que permanece é de como situar a transferência, ou seja, qual o endereçamento da suposição de saber que permitiria essa elaboração. Certamente não seria ao professor, mas este deve acolher o endereçamento ao texto da psicanálise, ao que foi e vem sendo produzido no campo psicanalítico, para permitir que esse "trabalho através" aconteça.

\section{Pós-graduaÇão Senso estrito: o Sentido do Durcharbeitung}

Qual o sentido de um mestrado ou doutorado para um psicanalista? A idéia central é que ali se faz um professor e/ou um pesquisador universitário, jamais um psicanalista. Quanto a isso não há dúvidas. Mas tem sido cada vez maior a procura por psicanalistas de uma pós-graduação senso estrito. Podemos dizer que se trata de uma nova expansão do mercado de trabalho no ensino da psicanálise, uma retomada da universidade. Muito bem, não há problema nisso. O que pode tornar as coisas mais interessantes é constatar que um psicanalista pode-se valer dessa experiência de um modo interessante, que não é prerrogativa exclusiva sua, mas que depende de uma determinada posição subjetiva muitas vezes difícil de se atingir, que é análoga à posição do analisando no trabalho analítico. Há um desafio inerente à exigência de trabalho na produção de uma tese que coloca em cena o sujeito como autor. E dessa vez não é como autor de sua própria história, mas como algo a ser sustentado como trabalho próprio, principalmente no caso do doutorado.

Sendo assim, aqui só tem sentido o Durcharbeitung. Fora isso, estamos novamente sob a égide do discurso universitário sem apelação. O saber imperando como semblante produzindo sujeitos divididos. Portanto, o sentido do Durcharbeitung é fazer o giro de um discurso ao outro atravessando os dois discursos, da histeria e do analista. A partir do discurso histérico, o sujeito dividido $(\exists)$ se dirige ao enigmático $(\diamond)$ de um conceito-chave da psicanálise, de algo que lhe provoca uma questão, e se põe a trabalhar na direção de produzir saber $(\mathbf{V})$, mas é movido pelo objeto causa de desejo $(\forall)$ ao modo da parte superior da estrutura do discurso analítico. O objeto a opera acima da barra, diferente do discurso histérico no qual sua função de "mais-de-gozar" fica elidida. É nesse deslocamento do gozo ao desejo que o a é agente da causa. A fórmula da elaboração fica assim:

\section{$\forall \downarrow \exists J$}

Como alunos, os psicanalistas na universidade podem dar provas de sua elaboração de saber. O produto, a tese, pode ser uma boa oportunidade para a dissolução da transferência e a apropriação de um saber para sustentar a transmissão por meio de um ensino que é singular, mas tornado público. A passagem pelo exame da banca, que se costuma chamar de "defesa" de tese, deveria ir nessa mesma direção, isto é, escapar ao discurso universitário como mera demonstração de saber, prova de saber para fazer reinar o $\mathbf{V}$, e pôr à prova a elaboração de saber. Aí temos uma autoria a partir da psicanálise, do percurso de cada um, caso a caso, marcando seu estilo, e, por que não dizer, seu sinthoma. Deve haver algo de um "passe" nesse processo que culmina com um ato de afirmação de um dizer e de uma escrita. Esse deve ser o sentido da apresentação pública de uma tese. 
Os cânones universitários permitem isso, a tecnologia acadêmica tem suas regras formais, mas a formalização do saber pode e deve ocorrer a partir da elaboração do sujeito em sua autoria, por sua conta e risco, causado pelo objeto que o põe a trabalhar e caucionado pelo orientador, que aqui deve estar como garantia do trabalho além da interlocução necessária. Função simbólica por excelência. É para isso que temos psicanalistas na pós-graduação. Senão, tudo não passa de uma acumulação de saber para cair na malha burocrática dos currículos e titulações.

Quanto ao trabalho de pesquisa, não é o caso aqui de discutir a psicanálise do ponto de vista epistemológico, se está ou não no campo da ciência, qual o seu método etc. ${ }^{8}$ A pesquisa segue na via do pesquisador que interroga o instituído para produzir um saber que só pode ser contingente, exploratório, provisório, saber furado, mas também formalizado. O matema é um bom exemplo do que deve ser formalizado na pesquisa psicanalítica. O pesquisador opera desde o discurso da histeria, e deve ir na direção dessa formalização para sustentar uma transmissão da psicanálise no que cada um "põe algo de si" como diz Lacan na abertura de seus Escritos.

\section{De QUe SABER SE TRATA PARA A PSICANÁlise NA UNIVERSIDADE?}

Na universidade o tout savoir está presente, é inevitável. Mas, como barreira a esse tudo saber, temos a produção de cada um que, além de contar como unidade de valor, retorna para o sujeito trazendo algo de sua verdade que se articula com um saber. Aqui comparece o discurso analítico recolocando o saber no lugar da verdade do sujeito. Dessa vez não é como resultante de uma análise, mas como resultante de uma elaboração, de um "trabalho através", um Durcharbeitung, que se faz na tessitura de uma tese, de um escrito que porta uma resposta.

O que diferencia o trabalho do psicanalista na universidade no caso de produzir uma tese é que a relação transferencial com o objeto de estudo, marcado por determinados significantes, é decisiva. A elaboração põe em jogo a relação do sujeito/autor com a verdade em todo esse percurso. Mas qual a diferença ao se levar em conta o inconsciente? Pode-se falar "sobre" o inconsciente, "sobre" a psicanálise, como qualquer outra teoria. Ao se teorizar sobre isso voltamos à mesma posição do "teórico". O efeito de zerar um saber sabido, e retomá-lo para assumir uma autoria, é uma tomada de posição que serve como fundamento do trabalho.

Quanto ao orientador, ele opera ao modo do cartel, sustentando a transferência de trabalho como Mais Um, ou seja, o que garante e sustenta a feitura do produto que é do sujeito, de sua autoria, e pode envolver transferências diversas com outros autores, desde que seus princípios sejam partilhados com o orientador. Há um partilhar o saber nesse movimento e não uma imposição do saber que divide o sujeito (discurso universitário). Uma tese não deixa de ser produto da divisão do sujeito, mas há um sujeito em ato, que se afirma na sua autoria, até podemos dizer numa certeza antecipada, com sua "tese" (o que funda o trabalho, não o texto em si). Do lado do orientador, ocorre o giro retrógrado do discurso universitário para o discurso do analista deixando a histerização (discurso histérico) como um primeiro momento do orientando para chegar à elaboração, produzir seu texto 
como e "cuspir" que o move, que vem desde o lugar da verdade no discurso universitário, até o lugar do produto / resto no discurso do analista. Aí a tese tem o seu final, seu destino, que não é a gaveta, nem apenas a biblioteca, e sim o que representa o sujeito (autor) para os significantes do mundo ( $\mathrm{Sn}$ ). O próprio ato de dar um título, o nome da tese, é um indicador importante disso e opera como $\diamond$. E muitas vezes só aparece no final do trabalho conferindo sua marca.

Nem todas as teses de psicanálise passam por essa "operação", e outras, com outros temas, podem ter esse percurso, mas tanto para o autor quanto para o orientador, em se tratando de psicanalistas, esse desafio é fundante, é condição de trabalho, e dá uma outra dimensão à questão da reprodução do saber no discurso universitário.

No caso da pesquisa, o sujeito extrai de seu sintoma, sua questão de estudo. $\mathrm{Na}$ maioria das vezes sem perceber. Muitas pesquisas decorrem de um desafio maior de elaborar uma tese que deve ser "defendida". Mas, mesmo seguindo os cânones acadêmicos na formatação, o sujeito aí está, não pode ser totalmente elidido pelo saber. Portanto, põe algo de si nesse trabalho, um estilo, um modo de dizer que visa um ponto de basta, um término, não da análise, mas de um percurso. O trabalho de elaboração em uma tese se impõe até sua assunção em ato pela autoria. As chamadas defesas de teses, antes de serem "defesas", são essa operação de dizer em ato e sustentar o que foi escrito afirmando uma autoria. Essa autoria é o diferencial pelo qual cada um faz seu trabalho, cada um põe algo de si. E esse algo é seu estilo.

Caminhemos um pouco mais nessa via. Se o estilo é o melhor destino do sintoma para o sujeito, como sustentá-lo? Em outras palavras, como o sujeito sustenta seu estilo no laço social? Só nos resta uma direção a tomar: a direção do desejo. E é essa direção que sustenta a psicanálise para além de uma técnica ou método, a ética do desejo. Não abrir mão de seu desejo, é a recomendação que Lacan faz para manter "vivo" o sujeito. ${ }^{9}$ De certo modo podemos dizer que o desejo é o sujeito.

Retomando nossa questão sobre o saber, que relação teria com o desejo? $\mathrm{O}$ que podemos concluir é justamente o que nos orienta para o ensino; podemos até mesmo pensar em qualquer ensino e não só o da psicanálise. $\mathrm{O}$ que se pode transmitir do que se ensina é um desejo de saber. $\mathrm{O}$ desejo de cada sujeito em direção ao saber pode tomar diferentes vias. Pode ser em relação à falta de saber que segue na direção do saber semblante (tudo saber); ou ainda na direção do saber do Outro, que também é o lugar do saber inconsciente, saber como ficção, a ficção dos textos. Mas pode ser na direção do saber como falta, no lugar da verdade, o que falta ao Outro $\Sigma(\%)$. O desejo de saber que tem a marca da psicanálise se inscreve nesse ponto.

O que verdadeiramente se transmite em última instância é sempre uma falta. Falta esta que deve operar como causa de desejo. $\mathrm{Na}$ universidade, nossa tarefa primordial é transmitir esse desejo de saber como falta no saber, para que cada um recolha os elementos do que lhe provocou alguma diferença e faça deles sua produção, marcando seu estilo. Eis o que podemos fazer para além do discurso universitário, entre o discurso histérico e o analítico. 


\section{NoTAS}

${ }^{1} \mathrm{O}$ material histórico aqui apresentado foi colhido em pesquisa para dissertação de mestrado intitulada "Estratégias de Difusão do Movimento Psicanalítico no Rio de Janeiro: 1970-1983" PUC/RJ, 1984.

2 Este texto é contemporâneo de dois textos dos Escritos (LACAN, 1998) cruciais para localizar a questão do ensino e da transmissão da psicanálise: "Situação da psicanálise e formação do psicanalista em 1956" (p. 461-495) e "A instância da letra no inconsciente ou a razão desde Freud" (p. 496-533).

3 Trata-se da École Freudienne de Paris, fundada em 1964, no mesmo ano em que é desligado da IPA (a excomunhão, como disse na abertura do Seminário XI). Lacan pretende aí avançar seu ensino, segundo ele "no campo aberto por Freud" para "restaurar a lâmina cortante de sua verdade" (cf. Ata da Fundação da École Freudienne em Documentos para uma escola, Revista da Letra Freudiana, ano I, n ${ }^{\circ} 0, \mathrm{~s} / \mathrm{d}, \mathrm{p} .17$ )

${ }^{4}$ Sobre isso ver o conhecido texto de Freud de 1919 "Sobre o Ensino da Psicanálise nas Universidades", v. XVII, ESB/SE.

5 Sobre os quatro discursos, ver Lacan (1969-70/1992, 1971-72 inédito).

${ }^{6}$ Ver nota $n^{\circ} 4$ acima.

7 Sobre o tema, ver Figueiredo, A. C. \& Vieira, M. A. (1997).

8 Já existe uma boa literatura sobre essa discussão da pesquisa em psicanálise, na medida em que psicanalistas vêm tendo essa função na universidade. Recomendo algumas leituras como: Figueiredo, A. C. (2001); Figueiredo, A. C. \& Vieira, M. A. (2002); Alberti, S. \& Elia, L. (2000).

9 Ver Lacan em seu Seminário 7 sobre a Ética da Psicanálise (1959/1960) no qual introduz a questão do desejo, apontando sua diferença em relação ao amor, à crença e à autonomia, mostrando o preço que cada um tem a pagar por seu acesso ao desejo como constituindo seu próprio lugar de sujeito.

\section{REFERÊNCIAS}

ALBERTI, S.; ELIA, L. (Org.). Clínica e Pesquisa em Psicanálise. Rio de Janeiro: Contra Capa, 2000.

FIGUEIREDO, A. C. Estratégias de Difusão do Movimento Psicanalítico no Rio de Janeiro: 1970-1983. 1984. Dissertação (Mestrado)-Pontifícia Universidade Católica do Rio de Janeiro - PUC/RJ, Rio de Janeiro, 1984.

. (Org.). Psicanálise, Pesquisa e Clínica. Rio de Janeiro: Coleções IPUB; CUCA-IPUB/UFRJ, 2001.

FIGUEIREDO, A. C.; VIEIRA, M. A. A supervisão: do saber sobre a psicanálise ao saber psicanalítico. Cadernos IPUB, Rio de Janeiro, n. 9, p.87-95, 1997. Instituto de Psiquiatria IPUB/UFRJ.

. Psicanálise e ciência: uma questão de método. In: BEIVIDAS, W. (Org.). Psicanálise, pesquisa e universidade. Rio de Janeiro: Contra Capa, 2002. 
FREUD, S. Sobre o ensino da psicanálise nas universidades (1919). In:

Obras psicológicas completas de Sigmund Freud. Rio de Janeiro: Imago, 1988. v. XVII. Edição Standard Brasileira.

LACAN, J. A psicanálise e seu ensino (1957). In: . Escritos. Rio de Janeiro, J. Zahar, 1998. p. 438-460. Situação da psicanálise e formação do psicanalista (1956). In:

Escritos. Rio de Janeiro, J. Zahar, 1998. p. 461-495.

- A instância da letra no inconsciente ou a razão desde Freud (1957). In: Escritos. Rio de Janeiro, J. Zahar, 1998. p. 496-533.

Proposição de 9 de outubro de 1967 sobre o psicanalista da escola (1967).

Letra Freudiana: escola, psicanálise e transmissão, Rio de Janeiro, ano I, n. 0, 1981. p. 29-44.

. O Seminário - livro 7: a ética da psicanálise (1959-60) . Rio de Janeiro: J. Zahar, 1988.

O Seminário - livro 17: o avesso da psicanálise (1969-70). Rio de Janeiro: J. Zahar, 1992.

. O Saber do Psicanalista, seminário inédito, 1971-72. Centro de Estudos Freudianos de Recife (publicação para circulação interna), 2000-2001.

Recebido em: janeiro de 2006

Aceito em: dezembro de 2006 